\title{
Heart murmurs audible across the room in children with mitral valve prolapse
}

\author{
GARRICK I FIDDLER, OLIVE SCOTT \\ From the Department of Paediatric Cardiology, Killingbeck Hospital, Leeds
}

SUMMARY Three children are described in whom an unusual heart murmur was intermittently audible in the same room without a stethoscope. Subsequent investigations disclosed mitral valve prolapse in all three patients.

A century ago, Osler $^{1}$ drew attention to heart murmurs audible at some distance from the chest wall. He described in detail an otherwise healthy 12-year-old girl with an intermittent high pitched systolic murmur, which when present was audible across the room and altered in intensity with postural changes. He was impressed by "the absence of signs of grave heart disease". An earlier description of similar unusual murmurs appeared in Germany in $1878 .^{2}$

The aetiology of these murmurs, whether audible with or without a stethoscope, remained controversial and they were described as "whoops"3 and later as "praecordial honks". ${ }^{4}$ Rackley et al. ${ }^{4}$ were the first to suggest that the murmurs arose from the mitral valve. Leon et al. ${ }^{5}$ using intracardiac phonocardiography concluded from a study of nine patients that "these sounds were part of a spectrum of acoustical events associated with mitral incompetence".

We have recently encountered three children with similar findings to Osler's original case in whom subsequent investigations showed mitral valve prolapse.

\section{Material and methods}

M-mode echocardiography using standard techniques was performed using an Organon Teknika Ultrasonoscope interfaced with a strip chart recorder. In all the patients a $5 \mathrm{MHz}$ unfocused transducer was used. Phonocardiograms were recorded on a Cambridge recorder with a 100 to $600 \mathrm{~Hz}$ frequency range. Ambulatory electrocardiogram monitoring was performed using an Oxford Instruments analogue recorder.

Received for publication 7 January 1980

\section{Case reports}

CASE 1

A previously healthy girl was first seen at 10 years of age with a one-year history of an intermittent sound emanating from her chest in time with the heart beat. The sound was never present when she visited her family doctor, but was loud enough to be tape recorded at home by her parents and occurred in episodes lasting from two to 20 minutes. The recording revealed a high pitched "whooping sound". Physical examination was normal apart from a short grade $2 / 6$ systolic murmur in the mitral area. The chest $x$-ray was normal, as was the electrocardiogram apart from some minimal $T$ wave flattening in the inferior leads. She was not considered to have significant heart disease. When she was seen again six years later, she was still well and had experienced no further episodes of the chest sound for three years. She did, however, admit to being occasionally aware of her heart beating rapidly. The physical findings were unchanged, except that a mid-systolic click was now audible. The chest $x$-ray and electrocardiogram were unchanged. Echocardiography showed late systolic prolapse of both mitral leaflets with normal dimensions of the left atrium and left ventricle. Phonocardiography confirmed the presence of a short late systolic murmur, but no click was identified. Ambulatory electrocardiogram monitoring over a 48-hour period showed sinus rhythm with occasional runs of frequent multifocal ventricular ectopic beats and short periods of coupling.

CASE 2

A healthy girl was first seen at the age of 12 years. Her general practitioner had recently detected a 
murmur during an examination at the time of a respiratory infection. The patient, herself, had noticed an intermittent noise from her chest during the previous three months and on several occasions it had been heard by her parents in the same room. It had been first noted after she had stretched her arms above her head and it seemed to be related to exercise. Examination was within normal limits except for a short grade $2 / 6$ blowing mid-systolic murmur in the mitral area. The chest $x$-ray was normal as was the electrocardiogram apart from some flattened $T$ waves in the inferior leads. When seen again 18 months later she was well but was still aware of the noise, which tended to be audible when her arms were above her head. There were no symptoms referrable to the cardiovascular system. Physical findings were unchanged except for the presence of a mid-systolic click. The chest $x$-ray and electrocardiogram were unchanged. Echocardiography demonstrated late systolic prolapse of both mitral leaflets with normal chamber dimensions, while phonocardiography identified only a mid-systolic click (Fig.). Ambulatory electrocardiogram monitoring over a 48-hour period showed sinus rhythm with very occasional unifocal ventricular ectopic beats.

\section{CASE 3}

A boy was first seen at the age of 10 years. Two years previously he had been admitted to his local hospital with a diagnosis of pericarditis. For four days before admission he had severe vomiting with diarrhoea and on the day before admission, while straining to vomit, he suddenly became aware of a squeaking noise coming from his chest. The noise was also heard by his parents on entering his bedroom and caused them great concern. While in hospital the noise occurred intermittently and seemed related to posture, and because of these features it was thought to be a friction rub. After eight weeks' bed rest he was discharged and during outpatient follow-up he remained well, but he continued to notice the noise intermittently, especially after climbing stairs or with an involuntary Valsalva manoeuvre. Examination at our clinic was within normal limits except for a grade 2/6 late systolic murmur in the mitral area. The chest $x$-ray was normal and the electrocardiogram showed $T$ wave flattening in the inferior leads. Echocardiography showed late systolic prolapse of both mitral leaflets and increased amplitude of excursion of the anterior leaflet. The left atrial and left ventricular dimensions were normal. Phonocardiography demonstrated a quiet late systolic murmur and ambulatory electrocardiogram monitoring over a 48-hour period disclosed normal sinus rhythm.

\section{Discussion}

Mitral valve prolapse is now thought to be the most common cardiac valve disorder in adults. It has also been reported in children from the age of 2 years onwards. ${ }^{6}$ The clinical, electrocardiographic, radiological, and echocardiographic features have been well described since its recognition as a distinct clinical entity by Barlow in $1963 .^{6-9}$ Several reviews have mentioned patients being aware of their own murmurs, ${ }^{89}$ but to our present knowledge, only seven patients, including Osler's case, with murmurs loud enough to be heard across

Fig. Phonocardiogram and echocardiogram from case 2. Phonocardiogram recorded at apex demonstrates late systolic click (c). Echocardiogram demonstrates late systolic prolapse of the mitral valve-arrows. ECG, electrocardiogram; IVS, interventricular septum.

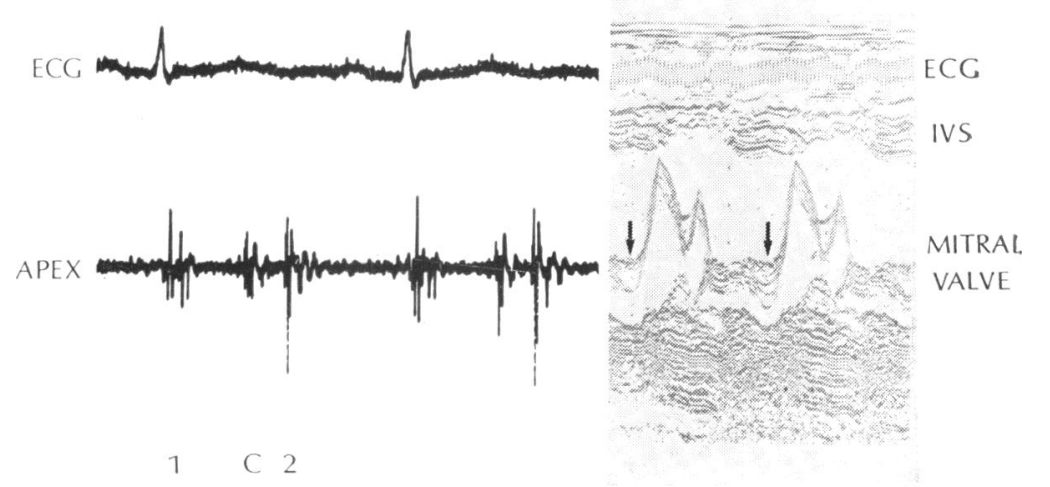


the room, have been described in detail. ${ }^{10-14} \mathrm{Six}$ were girls ranging in age from 3 to 12 years and one was a boy aged 12 years. This female preponderance, a well-recognised feature of mitral valve prolapse, was also seen in our patients. The intermittent nature of the murmurs and their appearance on exercise or excitement are features of the mitral valve prolapse syndrome and were present in our patients. Changes in left ventricular and diastolic dimension alter the timing of the mitral valve prolapse, and volume changes alter the intensity of the murmur.

Arrhythmias, both supraventricular and ventricular, especially after exercise, are common in patients with mitral valve prolapse. ${ }^{89}$ In the majority of patients, these arrhythmias are benign and not associated with symptoms, but in a few symptoms may be severe and even life threatening. ${ }^{15}$ One of our patients (case 1) had mild symptoms associated with an arrhythmia and runs of ventricular extrasystoles were detected on ambulatory monitoring.

The original diagnosis of pericarditis in case 3 is of interest as this diagnostic error has recently been reported. ${ }^{6}$

It thus appears that in many patients with murmurs audible across the room there is mitral valve prolapse. Echocardiography with or without provocative manoeuvres to produce the murmur is useful in detecting such patients. Despite the many different pathological processes incriminated in the aetiology of mitral valve prolapse, the outlook in the vast majority of patients is good. ${ }^{6}$ The risk of developing symptomatic arrhythmias or bacterial endocarditis is always present, however, and these patients require careful follow-up with antibiotic prophylaxis.

We wish to thank Drs Pugh, Morgan, and Cookson for referring the patients.

\section{References}

1 Osler W. On a remarkable heart-murmur, heard at a distance from chest-wall. Med Times Gaz 1880; 2: 432-3.
2 Ebstein W. Ueber die auf grössere Entfernung vom Kranken hörbaren löne und Geräusche des Herzens und der Brustaorta. Dtsch Arch Klin Med 1878; 22: 113-47.

3 McKusick VA. Cardiovascular sound in health and disease. Baltimore: Williams \& Wilkins, 1958: 202.

4 Rackley CE, Whalen RE, Floyd WL, Orgain ES, McIntosh HD. The praecordial honk. Am $\mathcal{F}$ Cardiol 1966; 17: 509-15.

5 Leon DF, Leonard JJ, Kroetz FW, Page WL, Shaver JA, Lancaster JF. Late systolic murmurs, clicks, and whoops arising from the mitral valve. Am Heart f 1966; 72: 325-36.

6 Jeresaty RM. Mitral valve prolapse. New York: Raven Press, 1979.

7 Barlow JB, Pocock WA, Marchand P, Denny M. The significance of late systolic murmurs. $A n l$ Heart $\mathcal{F} 1963 ; 66$ : 443-52.

8 Barlow JB, Pocock WA. The problem of nonejection systolic clicks and associated mitral systolic murmurs: emphasis on the billowing mitral leaflet syndrome. Am Heart $\mathcal{F}$ 1975; 90: 636-55.

9 Criley JM, Kissel GL. Prolapse of the mitral valvethe click and late systolic murmur syndrome. Frog Cardiol 1975; 4: 23-36.

10 Pickering D. Clicks, whoops and honks. Arch Dis Child 1972; 47: 731-4.

11 Segall HN. Autoauscultation in a patient with floppy mitral valve syndrome (letter). Am Heart $\mathcal{f} 1976 ; 91$ : 269-72.

12 Lababidi Z. Floppy mitral whistle heard across the room (letter). Am Heart $\mathcal{F}$ 1976; 91 : 825.

13 Young D. Noisy floppy mitral valve (letter). $\mathrm{Am}$ Heart f 1977; 93: 130.

14 Felner JM, Harwood S, Mond H, Plauth W, Brinsfield D, Schlant RC. Systolic honks in young children. Am $\mathcal{F}$ Cardiol 1977; 40: 206-11.

15 Campbell RWF, Godman MG, Fiddler GI, Marquis RM, Julian DG. Ventricular arrhythmias in syndrome of balloon deformity of mitral valve. $\mathrm{Br}$ Heart f 1976; 38: 1053-7.

Requests for reprints to Dr Garrick I Fiddler, Department of Paediatric Cardiology, Killingbeck Hospital, York Road, Leeds LS14 6UQ. 